\title{
Central role of detachment faults in accretion of slow spreading oceanic lithosphere
}

\author{
J. Escartín ${ }^{*}$, D. K. Smith ${ }^{\dagger}$ J. Cann ${ }^{\infty}$, H. Schouten ${ }^{\dagger}$, C. H. Langmuir ${ }^{\S} \&$ S. Escrig ${ }^{\S}$
}

"Marine Geosciences Group, CNRS - Institut de Physique du Globe de Paris, 4 Pl.

Jussieu, 75252 Paris Cedex 05, France; 'Geology and Geophysics Dept., Woods Hole

Oceanog. Inst., Woods Hole, MA 02543, USA; ${ }^{\infty}$ School of Earth and Environment, University of Leeds, Leeds LS2 9JT, England; ${ }^{\S}$ Dept. of Earth and Planetary Sciences, Harvard University, Cambridge MA 02138, USA.

The formation of oceanic detachment faults is well established from inactive, corrugated fault planes exposed on seafloor formed along ridges spreading at less than $80 \mathrm{~km} / \mathrm{My}^{1-4}$. These faults can accommodate extension for up to 1-3 $\mathrm{Myrs}^{5}$, and are associated with one of two contrasting modes of accretion operating along the northern Mid-Atlantic Ridge (MAR). The first is symmetrical accretion, dominated by magmatic processes with subsidiary high-angle faulting and formation of abyssal hills on both flanks. The second is asymmetrical accretion involving an active detachment fault ${ }^{6}$ along one ridge flank. An examination of $\sim 2500 \mathrm{~km}$ of the MAR between 12.5 and $35^{\circ} \mathrm{N}$ reveals asymmetrical accretion along almost half of the ridge. Hydrothermal activity identified to date in the study region is closely associated with asymmetrical accretion, which also exhibits highlevels of near continuous hydroacoustically and teleseismically recorded seismicity. Enhanced seismicity is probably generated along detachment faults accommodating a sizeable proportion of the total plate separation. In contrast, symmetrical segments have lower levels of seismicity, which concentrates primarily at their ends. Basalts erupted along asymmetrical segments have compositions that are consistent with crystallization at higher pressures than basalts from symmetrical segments, and with lower extents of partial melting of the mantle. 
Both seismic and geochemical evidence indicate that the axial lithosphere is thicker and colder at asymmetrical sections of the ridge, either because associated hydrothermal circulation efficiently penetrates to greater depths, or because the rising mantle is cooler. We suggest that much of the variability in seafloor morphology, seismicity and basalt chemistry found along slow-spreading ridges can be thus attributed to the frequent involvement of detachments in oceanic lithospheric accretion.

The large fields of detachment surfaces recently identified in oceanic crust formed along the slow spreading MAR and ultra-slow spreading South-West Indian Ridge $(\mathrm{SWIR})^{3,6}$ demonstrate the involvement of these structures in the accretion of a larger portion of the oceanic lithosphere than previously inferred from seafloor corrugated planes alone ${ }^{7}$. The resulting seafloor morphology and lithospheric structure on the flanks of the ridge axis are strongly asymmetrical ${ }^{3}$ and differ from the more regular and roughly symmetrical axis-parallel abyssal hill fabric believed to characterize 'normal' slow-spreading seafloor. The abyssal hill morphology is caused by ridge-parallel, highangle faulting of volcanic seafloor ${ }^{8}$ (Figures 1a-c). In contrast, detachment-related terrain is caused by long-lived steep, normal faults initiated beneath the rift valley floor that rotate to low angles as their footwalls are exposed ${ }^{7,8}$. Distinctive narrow ridges with steep outward-facing slopes that are often curved in plan view develop near exposed detachments at the seafloor, and bound deep swales ${ }^{7}$ (Figures 1d-e), producing blocky and chaotic terrain ${ }^{7,9}$. The asymmetric nature of accretion in the presence of detachments is also observed in the overall lithospheric structure, composition and geophysical character wherever data are available ${ }^{3,4,10}$. The MAR lacks the broad ridges only found along the melt-poor SWIR, likely a manifestation of detachment faulting that is different from striated fault planes and associated structure ${ }^{3}$. 
Multibeam bathymetry data are available for most of the northern MAR and its flanks between the Marathon and the Oceanographer Fracture Zones $\left(12^{\circ} 40\right.$ ’ $\mathrm{N}$ to $35^{\circ} 15^{\prime} \mathrm{N}$, Figure 1a). We use the systematic morphological differences between abyssal hill terrain (Figures 1b-c) and detachment-related terrain ${ }^{7}$ (Figures 1d-e) to re-interpret the existing bathymetry on both flanks of these $\sim 2500 \mathrm{~km}$ of ridge. We quantify the importance of detachment faulting in lithospheric accretion, and investigate relationships between the mode of accretion and seismic character of the spreading axis and geochemistry of erupted basalts (Figures 2-3). Our analysis shows that "symmetrical segments" with abyssal hill terrain flanking both sides and no detachment faulting occupy $>30 \%$ of the axis. "Asymmetrical accretion" where detachment fauting occurs along one flank of the axis make up $\sim 50 \%$ of the ridge axis. The remaining $\sim 20 \%$ of the axis is unclassified owing to limited bathymetric coverage or to unclear morphology at discontinuities and oblique ridge sections (see interpreted maps and Table 1 in Supplementary Information). While there is no apparent correlation with axial depth (Figure 2a), nor a continuous along-axis trend in the relative distribution of accretionary modes, there is a broad wavelength change. Detachments are dominant between the Marathon and Fifteen-Twenty Fracture Zones, with 70\% of the ridge axis accreting asymmetrically, and they are practically absent between the Hayes and Oceanographer Fracture Zones, immediately south of the Azores hotspot, where less than $15 \%$ of the axis accretes asymmetrically (Figure $2 a$ ).

There is an excellent correlation between mode of accretion and seismicity at the ridge axis. This section of the MAR was hydroacoustically monitored between January 1999 and September $2003^{11}$. The hydroacoustic catalogue is complementary to the $>30$ year teleseismic catalogue, as it records smaller magnitude events (magnitude of completeness of 3 and 5 , respectively $\left.{ }^{12}\right)$, over a shorter period of time $(<5$ vs. $>30$ years). Both seismic catalogues show that detachment-dominated, asymmetrical ridge sections host $\sim 75 \%$ more hydroacoustic events and $\sim 65 \%$ more teleseismic events than 
symmetrical segments (Figure $2 \mathrm{~b}$ and $\mathrm{c}$ ). The concentration of seismicity at segments shown to have active detachment faults (Figures 1d-e), such as the Logachev massif south of the Fifteen-Twenty Fracture zone and the TAG detachment fault near $26^{\circ} \mathrm{N}^{6,7,13}$, is thus a general pattern. Active detachments also control the zones of sustained seismicity, which lack shock-aftershock sequences that were previously identified along the northern $\mathrm{MAR}^{14}$. Differences between the hydrophone and teleseismic patterns (Figures $2 \mathrm{~b}-\mathrm{c}$ ) probably arise from temporal variability in seismicity, and from a secondary control on seismicity by other factors in addition to detachment faulting. For example, shock-aftershock sequences generated along steep normal faults in the flanks of the MAR may result in elevated rates of hydrophone events along symmetrical segments, such as those near $24.25^{\circ} \mathrm{N}^{12}$, which are not observed in the longer-term teleseismic data (Figures 2b-c). Complex tectonic processes at segment ends and oblique zones can also significantly increase seismicity, even if segments show little or no seismicity at their centres (Figures $1 b-c)^{14}$.

Comparison of microseismicity results with regional seismic patterns allows us to constrain the nature of the zones of elevated and sustained seismicity. An 8-month microseismic experiment at the TAG hydrothermal field $\left(26.1^{\circ} \mathrm{N}\right)$ shows deformation along the active detachment fault accommodated by continuous creep associated with steady hydroacoustic event rates (Figure 1d). Microseismicity events at ridge sections with active detachments $\left(\mathrm{TAG}^{13,15}, 23^{\circ} \mathrm{N}^{16}\right)$ are observed down to $7-8 \mathrm{~km}$ below seafloor, with the interpreted fault rooting directly below the neovolcanic zone ${ }^{13}$. In contrast, at the centre of symmetrical segments $\left(35^{\circ} \mathrm{N}^{17}\right.$ and Figure $\left.1 \mathrm{~b}, 29^{\circ} \mathrm{N}^{18}\right)$ events extend to maximum depths of 5-6 km, 1-3 km shallower than near detachments (see Figure 2 in Supplementary Information).

There is a close association of hydrothermal activity and asymmetrical accretion. Ridge sections flanked by active detachments host 7 out of the 8 known active or recent 
hydrothermal vent fields in the area, and are overlain by 6 out of 7 identified hydrothermal plumes ${ }^{19}$ in the water column (Figure $2 \mathrm{a}$ ). There is also evidence for hightemperature fluid circulation along detachment faults ${ }^{20,21}$, suggesting a direct link between hydrothermal activity and deformation associated with the faults. The data thus point to a link, albeit complex, between extension on detachments and hydrothermal activity, consistent with a thicker lithosphere at asymmetrical relative to symmetrical ridge sections.

The two modes of lithospheric accretion from our study area also exhibit differences in the geochemistry of basalts. Trace element and to some extent major element data are subject to regional mantle heterogeneities ${ }^{22}$, in addition to local variability $^{23}$. We thus restrict our investigation to pairs of adjacent segments, one of which has asymmetrical and the other symmetrical accretion, and from both of which multiple chemical analyses are available. We note, however, that the trends described here are present when all data from the study area are considered, and despite significant overlap between basalt compositions from each of the two modes of accretion (See Figure 2 in Supplementary Information). Basalts from symmetrical segments show less compositional variation, and generally reflect lower eruption temperatures, as expressed by the $\mathrm{MgO}$ contents of the lavas. Asymmetrical segments yield more primitive (higher temperature) basaltic compositions, having undergone less crystal fractionation than basalts from symmetrical segments. There are also chemical offsets at constant $\mathrm{MgO}$ for major elements. Samples from asymmetrical segments have higher $\mathrm{Na}_{2} \mathrm{O}$ and $\mathrm{FeO}$ and lower $\mathrm{CaO}$ than samples from symmetrical segments (Figures 3a-c).

Since there are only limited trace element data for adjacent symmetrical/asymmetrical ridge sections that can be used to compare chemical compositions, we can only compare the north (symmetrical, MARNOK) and south 
(asymmetrical, MARK) of the Kane fracture zone. For this pair of segments we compare the ratio of moderately incompatible elements, $\mathrm{Zr} / \mathrm{Y}$, which is not particularly influenced by mantle heterogeneity. The symmetrical MARNOK segment has lower and more homogeneous $\mathrm{Zr} / \mathrm{Y}$ ratios than the MARK segment (Figure 3d).

As shown by the liquid lines of descent due to cooling at different pressures (Figure 3), the variations in $\mathrm{FeO}$ and $\mathrm{CaO}$ contents are consistent with lower pressure fractionation for samples from symmetrical segments, and higher pressure fractionation for samples from asymmetrical segments. The greater homogenization of lavas at symmetrical segments could be achieved within magma reservoirs resulting from greater melt supply to lower pressures than at asymmetrical ridge sections. In addition to the pressure of crystallization, other processes near detachment faults such as meltrock reactions inferred from gabbros sampled along the Kane detachment ${ }^{24}$ may also contribute to the systematic compositional difference between basalts erupted along the two types of segments.

High pressure fractionation alone, however, does not fully account for the offset in $\mathrm{Na}_{2} \mathrm{O}$ contents, nor does it produce significant differences in the $\mathrm{Zr} / \mathrm{Y}$ ratio, which may result instead from changes in the extent of melting, or reflect mantle heterogeneities. Indeed, there are significant differences in incompatible element compositions of the two segments, with Ba contents, for example, varying by a factor of 2 , and $\mathrm{Ba} / \mathrm{Y}$ ratios in MARNOK of $0.4 \pm 0.1$ and in MARK of $0.23 \pm 0.06$. Since the MARNOK segment has the higher $\mathrm{Ba} / \mathrm{Y}$ ratio, it might be expected to have a higher $\mathrm{Zr} / \mathrm{Y}$ ratio, $\mathrm{Zr}$ being less compatible than $\mathrm{Y}$. However, $\mathrm{Zr} / \mathrm{Y}$ is lower in MARNOK than in MARK (Figure 3), opposite of what would be predicted from a mantle heterogeneity effect. These data thus suggest melting differences between symmetric and asymmetric segments. Further basalt analyses from other segment pairs are necessary to elucidate these questions. 
Accretion along slow-spreading ridges is thus dominated by two distinct modes of spreading and partitioning of deformation, that in turn are reflected in the thermal structure, magmatic system and hydrothermal circulation at the axis as illustrated in Figure 4. Accretion in the presence of detachments is highly asymmetrical, with approximately $50 \%$ of the plate separation accommodated along a single fault along one of the ridge flanks. Overall tectonic strain at symmetrical segments is probably much lower $(<20 \%)^{25-27}$, and distributed instead over multiple high angle normal faults that are active o several tens of $\mathrm{km}$ off-axis ${ }^{14}$. This difference in the amount of tectonic strain may be responsible for the high rates of seismicity at asymmetrical ridge sections relative to symmetrical ones. Increased hydrothermal cooling and lithospheric thickness in the presence of detachment faults will likely influence the underlying magmatic system. A deepening of the top of the melting regime can lead to a reduction of the extent of melting of the mantle. Once magma separates and ascends towards the surface, it cools, reacts and crystallizes. There is thus a natural association of the thicker lithosphere of asymmetrical segments, the lower extents of melting, the higher degree of melt-rock reactions, and the greater pressures of crystallization at asymmetrical segments compared to symmetrical segments. One important remaining problem is that of the origin of the detachment faulting. Do detachment faults establish because of enhanced hydrothermal cooling and fault weakening that leads to the development of long-lived faults? Or are they forced to form by lower temperatures of the rising mantle beneath the axis, and consequently decreased magma supply? There may be a positive feedback between these two effects, where increased cooling at the surface leads to decreased melt production at depth, and vice versa, causing small differences to be amplified to generate such widely different styles of lithospheric accretion.

Supplementary Information accompanies the paper on www.nature.com/nature

The authors have no competing interests. 
Correspondence and requests for materials should be addressed to J.E. (e-mail: escartin@ipgp.jussieu.fr).

Acknowledgements. This work was carried out during a during a 16-month visit to Harvard University and MIT by JE, and was supported by CNRS (JE), NSF (DKS, HS, JC, CL and SE), WHOI (JE, DKS, HS and JC), Harvard University (JE, CL and SE), Univ. of Leeds (JC), and MIT (JE). We thank M. Cannat and J. P. Canales for discussions and W. R. Buck and B. Ildefonse for comments.

Author contributions. All authors contributed to the interpretation and analysis of the data, which was led by JE. JE wrote the manuscript, with contributions from all the co-authors.

Figure 1. Bathymetry of the study area and examples of symmetrical and asymmetrical segments with associated seismicity. (a) Available multibeam bathymetric coverage data between the Marathon and Oceanographer Fracture Zones ${ }^{6,9,28}$. (b-c) Examples of linear ridge segments flanked by ridge-parallel abyssal hills resulting from high-angle normal faulting corresponding to symmetrical accretion at their centre. Seismicity concentrates at segment ends, while the centre shows no or very few events. (d-e) Examples of asymmetrically accreting ridge sections. The axis is flanked by active detachment faults, which are associated with elevated seismicity rates. Dashed red lines ( $d$ and $e$ ): termination of detachment towards the ridge axis; dots: hydroacoustic events ${ }^{11}$; open circles: teleseismic events.

Figure 2. Along-axis distribution of asymmetrical and symmetrical ridge sections and correlation with hydrothermal and seismic activity. (a) Along-axis bathymetric profile showing the two modes of lithospheric accretion interpreted from seafloor morphology and tectonic structure (see detailed interpreted maps in Figure 1 of Supplementary Information). Segments associated with active detachment faulting host the large majority of known vent fields (red circles; see Methods section) and identified hydrothermal plumes in the water column ${ }^{19}$. (b) 
The average frequency of hydroacoustic and (c) teleseismic events (c) per km of ridge axis is higher along asymmetrical than symmetrical segments.

Figure 3. Systematic differences in basalt chemistry from symmetrical and asymmetrical ridge sections. The systematic differences in $\mathrm{MgO}$ vs. $\mathrm{CaO}$ (a), FeO (b) and $\mathrm{Na}_{2} \mathrm{O}$ content (c) for three pairs of adjacent symmetrical and asymmetrical segments, and lines of liquid descent (black lines) showing the compositional evolution of basalts for different pressures of crystallization. Sufficient rare earth element data are only available for the ridge sections adjacent to the Kane Fracture zone, MARNOK to the north (symmetrical) and MARK to the south (asymmetrical). The $\mathrm{Zr} / \mathrm{Y}$ ratio (d) is higher for the southern MARK segment.

Figure 4. Across-axis sections corresponding to symmetrical and asymmetrical accretion and associate processes. (a) In asymmetrical ridge sections detachments accommodate roughly half of the plate separation tectonically along a single fault. They also host hydrothermal fields that can contribute to the thick lithosphere at the axis (up to $8 \mathrm{~km}$ ), inferred from microseismic data. This strain partitioning results in more elevated and sustained levels of seismicity than symmetrical segments (b), which accommodate a lower proportion of the plate spreading by faulting $(\sim 10 \%)$ over numerous faults on both flanks simultaneously, and in a thinner axial lithosphere $(<6 \mathrm{~km})$. This colder axial regime can reduce the melting column, favor reduced melt supply, and promote crystallization at deep levels relative to symmetrical segments. Alternatively, mantle anomalies may instead the cause of these along-axis variations in thermal regime and mode of accretion. 


\section{Methods Summary}

Multibeam bathymetry data have been obtained from the Marine Geoscience Data Service (MGDS, http://www.marine-geo.org) database ${ }^{28}$ and complemented with that of Smith et al. ${ }^{6,7}$. These data were used to identify the ridgeward termination of detachment terrain, and the extent of ridge-parallel abyssal hill terrain flanking the axis. Ridge sections were classified based on the presence of linear abyssal hill terrain on both flanks (symmetrical accretion), or of detachment terrain along one of the flanks (asymmetrical accretion). The remaining sections of the ridge axis were unclassified.

Seismicity data were obtained from the hydrophone catalog ${ }^{11}$ and from the NEIC teleseismic catalog (http://neic.usgs.gov/). So as to remove intraplate seismicity and that associated with off-axis deformation, we restricted our analysis to events in oceanic lithosphere younger than $3 \mathrm{Myr}$, based on the digital seafloor age map ${ }^{29}$. Seismicity rates were calculated from the total number of hydroacoustic (Figure 2b) and teleseismic events (Figure 2c) recorded, and the length of individual ridge sections showing symmetric, asymmetric, or undetermined accretion.

Geochemical data for basalt glass were obtained from the PETDB database ${ }^{30}$, and complemented with unpublished data (J. Cann and C. Langmuir). For the data analysis we selected those basalt analyses from rocks sampled along the axial volcanic ridge, the rift valley floor, or the flanking walls. We then selected those analyses that could be corrected for interlaboratory bias ${ }^{31}$, discarding the remaining data. Liquid lines for different pressures of crystallization shown in Figure 3 were calculated using an initial primitive basalt composition. 


\section{References}

1 Tucholke, B. E., Behn, M. D., Buck, W. R. et al. Role of melt supply in oceanic detachment faulting and formation of megamullions. Geology 36 (6), 455 (2008).

2 Cann, J. R., Blackman, D. K., Smith, D. K. et al. Corrugated slip surfaces formed at North Atlantic ridge-transform intersections. Nature 385, 329 (1997).

3 Cannat, M., Sauter, D., Mendel, V. et al. Modes of seafloor generation at a melt-poor ultraslow-spreading ridge. Geology 34 (7), 605 (2006).

4 Okino, K., Matsuda, K., Christie, D. M. et al. Development of oceanic detachment and asymmetric spreading at the Australian-Antarctic Discordance. Geochem, Geophys., Geosys. 5 (12), Q12012 (2004).

5 Tucholke, B. E., Lin, J., and Kleinrock, M. C. Megamullions and mullion structure defining oceanic metamorphic core complexes on the Mid-Atlantic Ridge. J. Geophys. Res. 103 (B5), 9857 (1998).

6 Smith, D. K., Cann, J. R., and Escartín, J. Widespread active detachment faulting and core complex formation near $13^{\circ} \mathrm{N}$ on the Mid-Atlantic Ridge. Nature 443, 440 (2006).

7 Smith, D. K., Escartin, J., Schouten, H. et al. Fault rotation and core complex formation: Significant processes in seafloor formation at slow spreading midocean ridges (Mid-Atlantic Ridge, $13-15^{\circ}$ N). Geochem, Geophys., Geosys. 9 (3), Q03003 (2008).

8 Buck, W. R., Lavier, L. L., and Poliakov, A. N. B. Modes of faulting at midocean ridges. Nature 434, 719 (2005).

9 Fujiwara, T., Lin, J., Matsumoto, P. B. et al. Crustal evolution of the MidAtlantic Ridge near the Fifteen-Twenty Fracture Zone in the last $5 \mathrm{Ma}$. Geochem, Geophys., Geosys. 4 (3), 10.1029/2002GC000364 (2003). 
${ }^{10}$ Canales, J. P., Collins, J. A., Escartin, J. et al. Seismic structure across the rift valley of the Mid-Atlantic ridge at $23^{\circ} 20^{\prime} \mathrm{N}$ (MARK area): Implications for crustal accretion processes at slow-spreading ridges. J. Geophys. Res. 105 (B12), 28411 (2000).

${ }^{11}$ Smith, D. K., Tolstoy, M., Fox, C. G. et al. Hydroacoustic monitoring of seismicity at the slow-spreading Mid-Atlantic Ridge. Geophys. Res. Lett. 29 (11), 10.1029/2001GL013912 (2002).

${ }^{12}$ Bohnenstiehl, D., Tolstoy, M., Dziak, R. P. et al. Aftershock sequences in the mid-ocean ridge environment: an analysis using hydroacoustic data.

Tectonophys. 354, 49 (2002).

${ }^{13}$ deMartin, B. J., Sohn, R. A., Canales, J. P. et al. Kinematics and geometry of active detachment faulting beneath the Trans-Atlantic Geotraverse (TAG) hydrothermal field on the Mid-Atlantic Ridge. Geology 35 (8), 711 (2007).

${ }^{14}$ Smith, D. K., Escartín, J., Cannat, M. et al. Spatial and temporal distribution of seismicity along the northern Mid-Atlantic Ridge $\left(15^{\circ}-35^{\circ} \mathrm{N}\right)$. J. Geophys. Res. 108 (B3), 10.1029/2002JB001964 (2003).

${ }^{15}$ Kong, L. S., Solomon, S. C., and Purdy, G. M. Microearthquake Characteristics of a mid-ocean ridge along-axis high. J. Geophys. Res. 97, 1659 (1992).

${ }^{16}$ Toomey, D. R., Purdy, G. M., Solomon, S. C. et al. Microearthquakes beneath the median valley of the Mid-Atlantic ridge near $23^{\circ} \mathrm{N}$ : hypocenters and focal mechanisms. J. Geophys. Res. 90, 5443 (1985).

${ }^{17}$ Barclay, A. H., Toomey, D. R., and Solomon, S. C. Microearthquake characteristics and crustal $\mathrm{Vp} / \mathrm{Vs}$ structure at the Mid-Atlantic Ridge, $35^{\circ} \mathrm{N} . J$. Geophys. Res. 106 (B2), 2017 (2001).

${ }^{18}$ Wolfe, C., Purdy, G. M., Toomey, D. R. et al. Microearthquake characteristics and crustal velocity structure at $29^{\circ} \mathrm{N}$ of the Mid-Atlantic Ridge: The architecture of a slow-spreading serment. J. Geophys. Res. 100 (B12), 24449 (1995). 
19 Klinkhammer, G., Rona, P., Greaves, M. et al. Hydrothermal manganese plumes in the Mid-Atlantic Ridge rift valley. Nature 314, 727 (1985).

20 McCaig, A., Cliff, R. A., Escartin, J. et al. Oceanic deachment faults focus very large volumes of black smoker fluids. Geology 35, 935 (2007).

21 Boschi, C., Früh-Green, G., Delacour, A. et al. Mass transfer and fluid flow during detachment faulting and development of an oceanic core complex, Atlantic Massif (MAR 30N). Geochem, Geophys., Geosys. 7 (1), Q01004 (2006).

22 Bougault, H., Dmitriev, L., Schilling, J. G. et al. Mantle heterogeneity from trace elements: MAR triple junction near $14^{\circ} \mathrm{N}$. Earth Planet Sci. Lett. 88, 27 (1988).

${ }^{23}$ Klein, E. and Langmuir, C. H. Local versus global variations in ocean ridge basalt composition: a reply. J. Geophys. Res. 94 (B4), 4241 (1989).

${ }^{24}$ Lissenberg, C. J. and Dick, H. J. B. Melt-rock reaction in the lower oceanic crust and its implications for the genesis of mid-ocean ridge basalt. Earth Planet Sci. Lett. 271, 311 (2008).

${ }^{25}$ Escartín, J., Cowie, P. A., Searle, R. C. et al. Quantifying tectonic strain and magmatic accretion at a slow spreading ridge segment, Mid-Atlantic Ridge, 29N. J. Geophys. Res. 104 (B5), 10421 (1999).

${ }^{26}$ Macdonald, K. C. and Luyendyk, B. P. Deep-Tow studies of the structure of the Mid-Atlantic Ridge crest near lat $37^{\circ} \mathrm{N}$. Geological Socety of America Bulletin 88, 621 (1977).

27 McAllister, E. and Cann, J. R., Initiation and evolution of boundary-wall faults along the Mid-Atlantic Ridge, 25-29 degrees N. In Tectonic, magmatic, hydrothermal and biological segmentation of mid-ocean ridges, edited by $\mathrm{C}$. J. MacLeod, P. A. Tyler, and C. L. Walker, Vol. 118, 29 (1996).

${ }^{28}$ Carbotte, S. M., Arko, R., Chayes, D. N. et al. New Integrated Data Management System for Ridge2000 and MARGINS Research. EOS Trans. Amer. Geophys. Union 85 (51), 553 (2004). 
${ }^{29}$ Müller, R. D., Roest, W. R., Royer, J.-Y. et al. Digital isochrons of the world's ocean floor. J. Geophys. Res. 102 (B2), 3211 (1997).

${ }^{30}$ Lehnert, K., Su, Y., Langmuir, C. H. et al. A global geochemical database structure for rocks. Geochem, Geophys., Geosys. 1, 1999 GC000026 (2000).

$31 \mathrm{Su}, \mathrm{Y} . \mathrm{J} ., \mathrm{Mid}-\mathrm{ocean}$ ridge basalt trace element systematics: constraints from database management, ICPMS analyses, data compilation and petrological modeling. Columbia University, (pp. 484) (2002). 


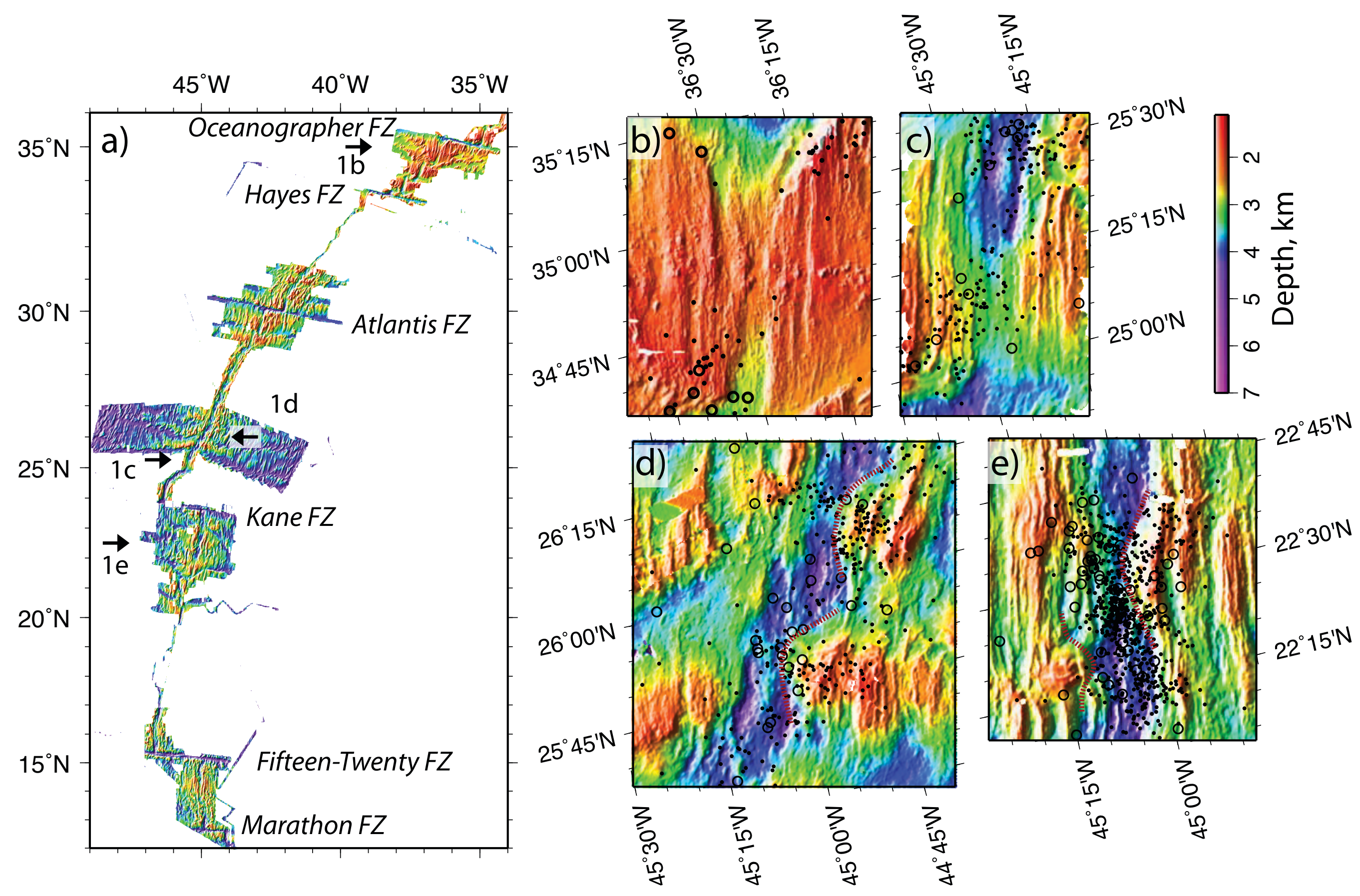

Escartin et al., Fig. 1 
a) Axial bathymetry and hydrothermalism
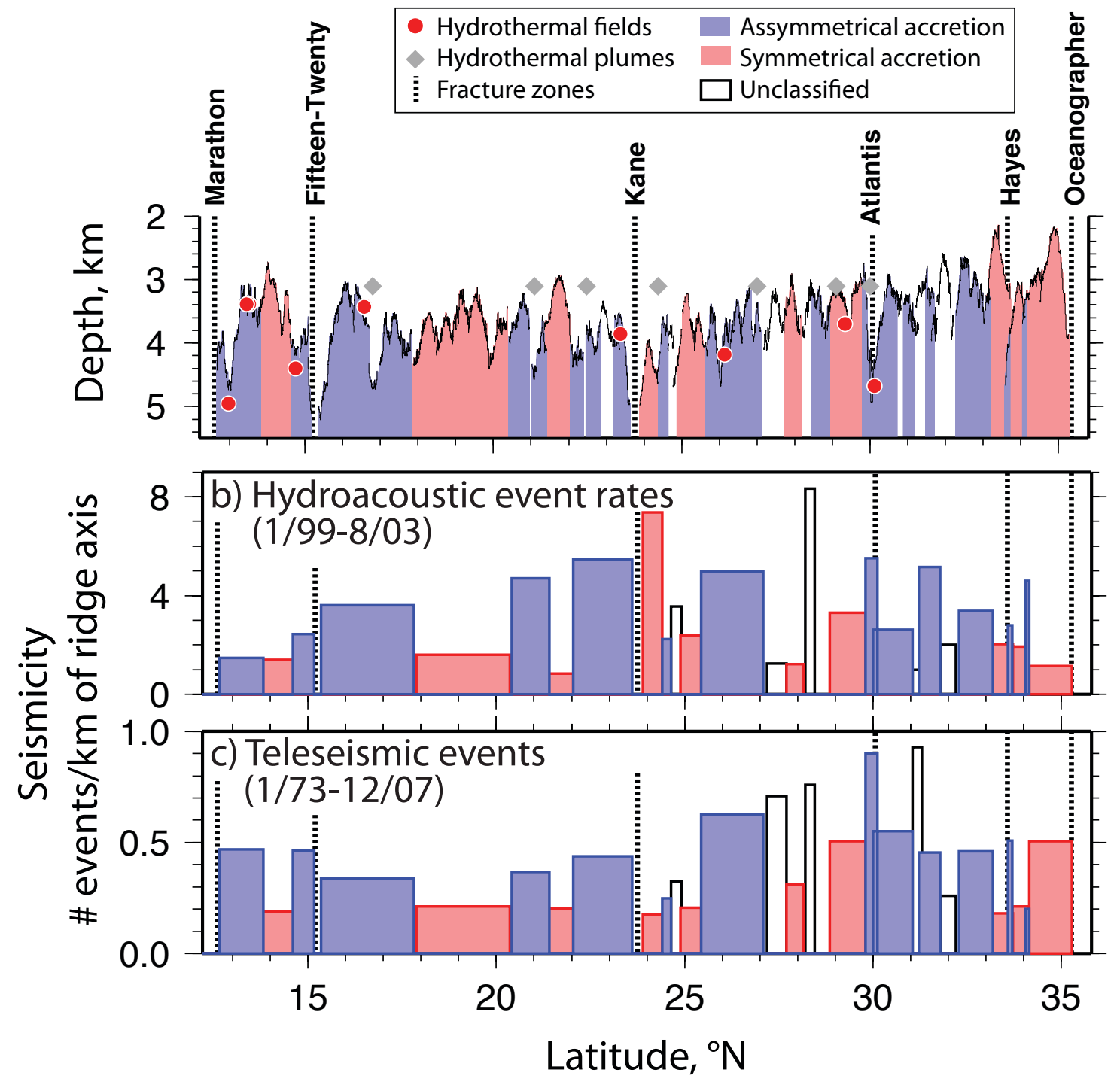

Escartin et al., Fig. 2 

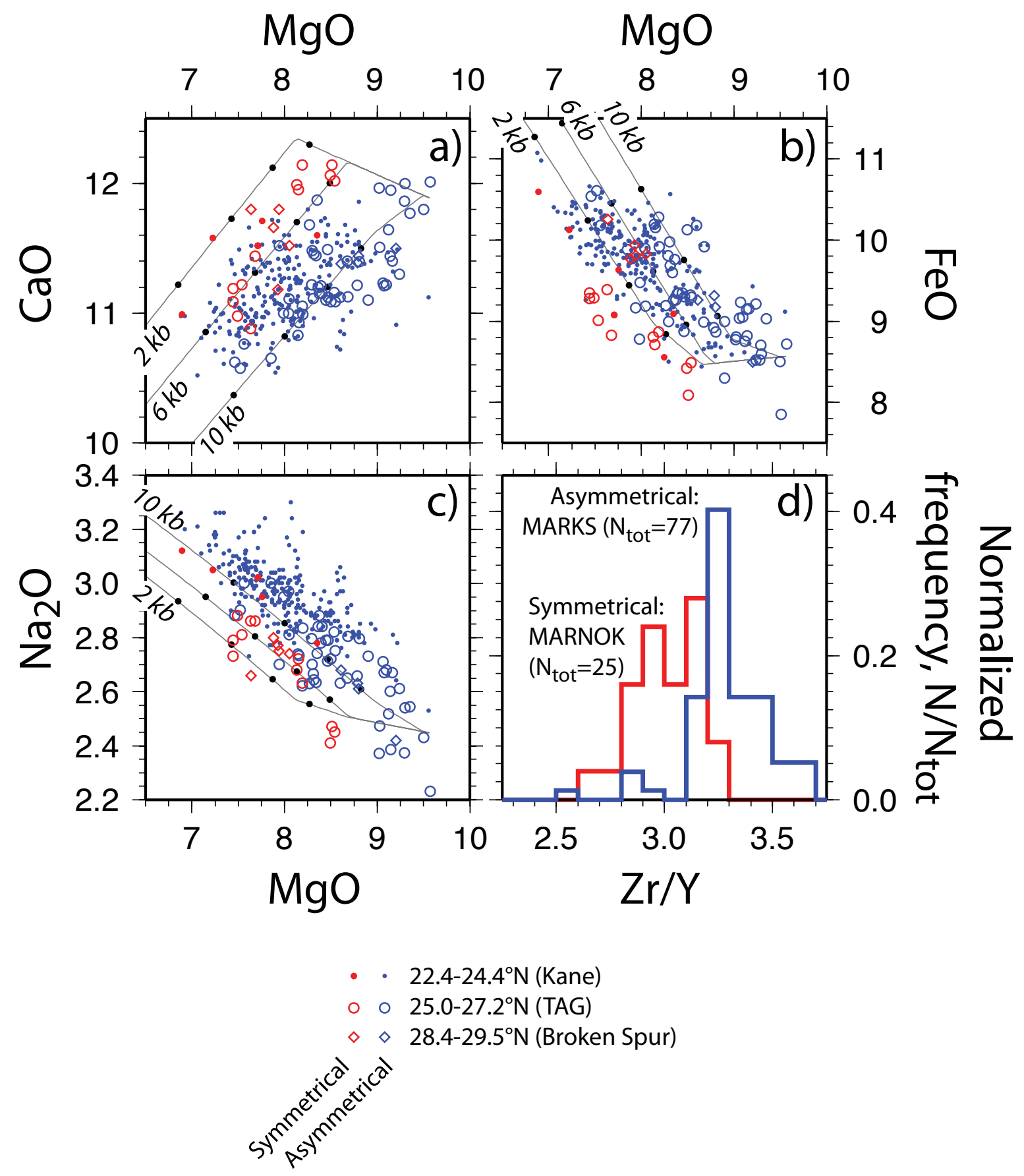

Escartin et al., Fig. 3 

a) Asymmetrical
b) Symmetrical

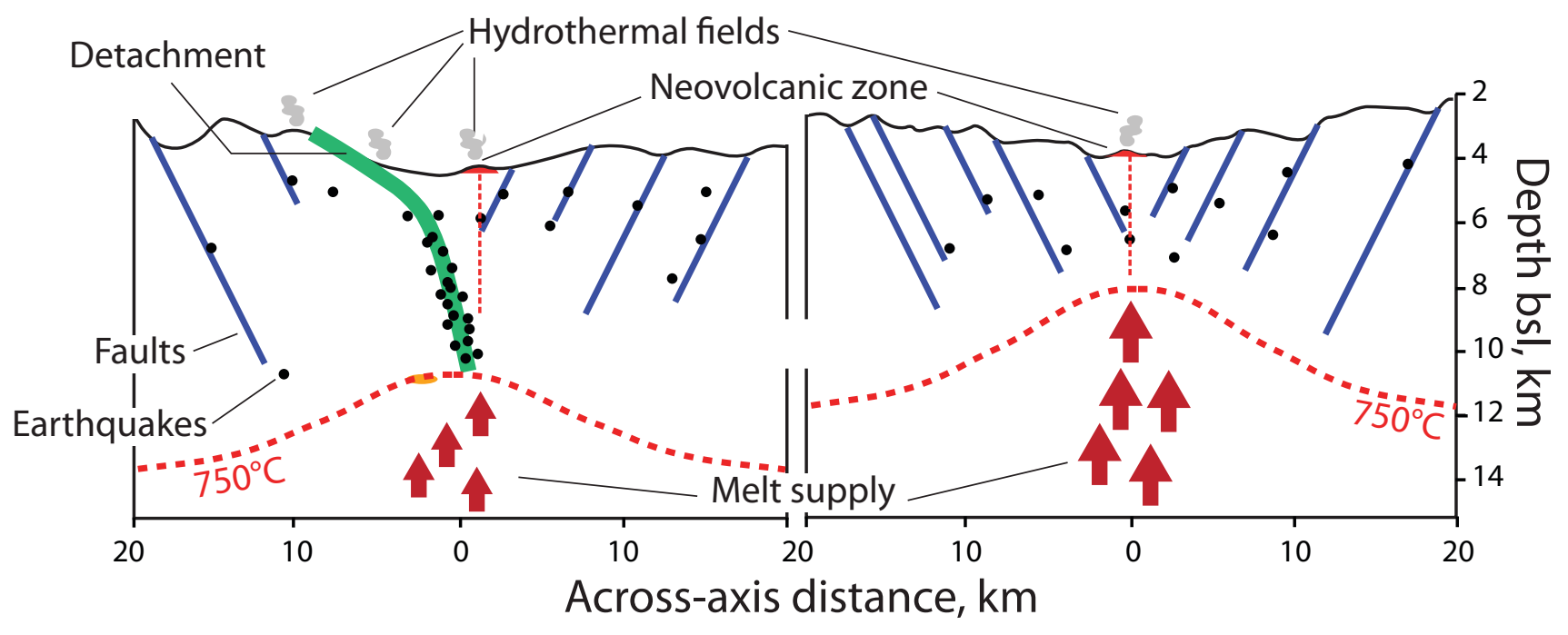

Escartin et al., Fig. 4 


\section{Methods}

Multibeam bathymetry grids along the study area were obtained from the Marine Geoscience Data Service (MGDS, http://www.marine-geo.org) ${ }^{28}$ and from Smith et al. ${ }^{6,7}$, and gridded at $\sim 100 \mathrm{~m}$. These data were used to define the ridge axis, either as indicated by axial volcanic ridges, or following the center of the rift valley in the absence of these structures, as reported in the interpreted maps from Figure 1 in the Supplementary Information. The ridgeward limit of both detachment terrain and volcanic abyssal hill terrain, as defined in the text, was digitized and also reported in the maps. The ridge axis was classified as corresponding to 'asymmetric accretion', 'symmetric accretion', or unclassified. The relative proportions of ridge axis reported in the paper are calculated from the ridge axis geometry presented in the maps. Proportions based on ridge length may differ from the proportions apparent in Figure 2, which corresponds to a latitudinal projection that does not take into account overlap, curvature, or gaps in ridge segmentation. Table 1 in the Supplementary Information provides relative proportions for each mode of accretion along ridge sections bound by major fracture zones, as well as their length.

Hydrophone events are from the NOAA hydroacoustic catalog (http://www.pmel.noaa.gov/vents/acoustics/autochart/GetPosit.html), which extends from $01 / 99$ to $09 / 03^{11}$. Telesesismic events are from the NEIC teleseismic catalog (http://neic.usgs.gov/) for the period 1973-2007. The digital seafloor age map ${ }^{29}$ was used to discard events occurring in lithosphere older than $3 \mathrm{Ma}$. As $>80 \%$ of the hydrophone and teleseismic events occur within $10 \mathrm{~km}$ of the ridge axis and corresponding to a spreading age of $\sim 1 \mathrm{Ma}^{14}$, the remaining events used in the analysis presented in the paper provide a good characterization of tectonic processes associated with accretion. Segments corresponding to symmetric, asymmetric and undetermined accretion were grouped into larger ridge sections with similar mode of accretion. The seismic rate (events per $\mathrm{km}$ ) for each ridge section is reported in Figures $2 \mathrm{~b}$ and $2 \mathrm{c}$, and were calculated using the total number of observed hydroacoustic and teleseismic events and the total length of ridge axis within each section.

Hydrothermal s--pites reported in Figure 2 of the paper and Figure 1 of the Supplementary Information include active vents found to date, and inactive hydrothermal fields within the rift valley that have thus been active in geologically recent times (probably less than 10's to 100's of thousands of years). From South to North these sites are: Ashadze at $12^{\circ} 58^{`} \mathrm{~N}^{32,33}, 13^{\circ} 30^{\prime} \mathrm{N}$ (inactive) $)^{34}$, Logachev at $14^{\circ} 45^{\prime} \mathrm{N}^{35}$, Krasnov (inactive) at $16^{\circ} 38^{\prime} \mathrm{N}^{36}$, 
Snake Pit at $23^{\circ} 22^{\prime} \mathrm{N}^{37}$, TAG at $26^{\circ} 08^{\prime} \mathrm{N}^{38}$, Broken Spur at $29^{\circ} 11^{\prime} \mathrm{N}^{39}$, and Lost City at $30^{\circ} 08^{\prime} \mathrm{N}^{40}$. Hydrothermal plumes in the water column reported in Figure 2 correspond to manganese anomalies generated by active hydrothermal vents within the rift valley ${ }^{41}$. In most cases the source at the seafloor of these plumes has not been directly observed.

The geochemical dataset included available mid-ocean ridge basalt glass analyses from PETDB (www.petdb.org) ${ }^{30}$, complemented with unpublished data from J. Cann ${ }^{42}$ and Ch. Langmuir ( 7700 glass analyses). The sample locations were verified to retain only the analyses from basalts sampled within the rift valley (axial volcanic ridges, rift valley floor, or inner rift valley walls). Major element data that could not be corrected for interlaboratory bias $^{31}$ were then discarded, and the remaining data ( 3200 analyses) were used in the paper (see Figures 1 and 3 in Supplementary Information). The final regional dataset shows differences in basalt geochemistry between asymmetrically and symmetrically accreting ridge sections, but a large overlap exists (Figure 3 in Supplementary Information) owing to regional variations mantle sources, among other factors. We have thus presented in Figure 3 results for three adjacent pairs of symmetric-asymmetric spreading sections, and therefore removing in each case long-wavelength compositional variations of the mantle that cannot be attributed to differences in the mode of accretion. In Figure 3 we also plot the liquid lines of descent for basalt to illustrate the effect of the pressure of crystallization on basalt composition. The initial composition corresponds to that of one of the most primitive basalt samples in the area. The liquid lines of descent are calculated using the program hbasalt $^{43}$.

\section{References}

32 Davydov, M. P., Aleksandrov, P. A., Perova, E. N. et al. Ferromanganese Deposits in the Ashadze-1 Hydrothermal Field (Mid-Atlantic Ridge, $12^{\circ} 58^{\prime} \mathrm{N}$ ). Doklady Earth Sciences 415A (6), 954 (2007).

${ }^{33}$ Beltenev, V., Ivanov, V., Shagin, A. et al. New hydrothermal sites at $13^{\circ} \mathrm{N}$, Mid Atlantic Ridge. InterRidge News 14, 14 (2005).

${ }^{34}$ Beltenev, V., Ivanov, V., Rozhdestvenskaya, I. et al. A new hydrothermal field at $13^{\circ} 30^{\prime} \mathrm{N}$ on the Mid-Atlantic Ridge. InterRidge News 16, 10 (2007). 
Batuyev, B. N., Krotov, A. G., Markov, V. F. et al. Massive sulphide deposits discovered and sampled at $14^{\circ} 45^{\prime} \mathrm{N}$, Mid-Atlantic Ridge. Bridge Newslett. 6, 6 (1994).

${ }^{36}$ Beltenev, V., Shagin, A., Markov, V. et al. A new hydrothermal field at $16^{\circ} 38.4^{\prime} \mathrm{N}$, $46^{\circ} 28.5^{\prime} \mathrm{W}$ on the Mid-Atlantic Ridge. InterRidge News 13, 5 (2004).

37 Ocean Drilling Program Leg 106 Scientific Party. Drilling the Snake Pit hydrotherma sulfite deposit on the Mid-Atlantic ridge, lat $23^{\circ} 22^{\prime} \mathrm{N}$. Geology 14 , 1004 (1986).

${ }^{38}$ Rona, P. A., Klinkhammer, G., Nelsen, T. A. et al. Black smokers, massive sulphides and vent biota at the Mid-Atlantic Ridge. Nature 321, 33 (1986).

39 James, R. H., Elderfield, H., and Palmer, M. R. The chemistry of hydrothermal fluids from the Broken Spur site, $29^{\circ} \mathrm{N}$ Mid-Atlantic Ridge. Geochimia et Cosmochimia Acta 59 (4), 651 (1995).

40 Kelley, D. S., Karson, J. A., Blackman, D. K. et al. An off-axis hydrothermal vent field near the Mid-Atlantic Ridge at $30^{\circ} \mathrm{N}$. Nature 411, 145 (2001).

${ }^{41}$ Klinkhammer, G., Elderfield, H., Greaves, M. et al. Manganese geochemistry near high-temperature vents in the Mid-Atlantic Ridge rift valley. Earth Planet Sci. Lett. 80, 230 (1986).

${ }^{42}$ Cann, J. and Smith, D. K. Evolution of volcanism and faulting in a segment of the Mid-Atlantic Ridge at 25N. Geochem, Geophys., Geosys. 6 (9), Q09008 (2005).

${ }^{43}$ Langmuir, C. H., Bezos, A., Escrig, S. et al., Chemical systematics and hydrous meling of the mantle in back-ark basins. In Back-arc spreading systems: Geological, biological, chemical and physical interactions, edited by David M. Christie, Charles R. Fisher, Sang-Mook Lee et al. (Geophysical Monograph Series, AGU), Vol. 166, 87 (2006). 